\title{
Effect of Using Movies to Enhance Personal Responsibility of University Students
}

\author{
Chuchai Smithikrai $^{1}$, Nathawat Longthong ${ }^{1} \&$ Chatwiboon Peijsel $^{1}$ \\ ${ }^{1}$ Department of Psychology, Faculty of Humanities, Chiang Mai University, Chiang Mai, Thailand \\ Correspondence: Chuchai Smithikrai, Department of Psychology, Faculty of Humanities, Chiang Mai University, \\ Chiang Mai 50200, Thailand. E-mail: csmithikrai@gmail.com
}

Received: May 7, 2014 Accepted: June 12, 2014 Online Published: February 12, 2015

doi:10.5539/ass.v11n5p1 URL: http://dx.doi.org/10.5539/ass.v11n5p1

\begin{abstract}
The objective of this study was to determine whether systematic movie-based training program can help developing personal responsibility in students. The research sample was 84 undergraduate students of a large public university in northern Thailand. Participants were randomly assigned to two experimental groups (movie+discussion and movie only) and one control group. Experimental group 1 and 2 viewed 5 movies which vividly portray personal responsibility during 5-weekly sessions. In addition, experimental group 1 participated in a 40-minute elaboration session about personal responsibility after viewing each movie. For the control group, participants received no intervention. Through a pretest, posttest control group experimental design, the two training groups experienced a significant increase in personal responsibility, while the randomly assigned control group showed no significant increase. In addition, results of the analysis of covariance indicated that systematic movie-based training positively developed personal responsibility, as the group variable predicted personal responsibility at post-training and 1-month follow-up periods while controlling for pre-training scores. Thus, the results of this experimental study provide support that personal responsibility can be enhanced through a five-period movie training intervention.
\end{abstract}

Keywords: personal responsibility, training with movies, university students

\section{Introduction}

The notion of personal responsibility is important and receives increasing attention from both academicians and public administrators, given current social problems (e.g., drug addiction, alcoholism, etc.) can be traced back to lack of personal responsibility. Personal responsibility is concerned with individuals taking accountability for their decisions and actions, together with the outcomes they create and their impacts on others (Linley \& Maltby, 2009). It is only with a willingness to take full responsibility for the choices made, that individuals can bounce back, renew their efforts, and change their course of action and consequences.

In sum, the concept of personal responsibility focuses on an individual's willingness to hold oneself responsible for resulting consequences; a sense of power and control to act and achieve one's goals; a belief in one's abilities; the likelihood that one will reflect upon one's choices and strategies. Additionally, personal responsibility is a future-focused, that is, a decision to take actions that will generate appropriate outcomes over time, rather than a past-focused accountability and culpability for previous actions (Linley \& Maltby, 2009).

It is, therefore, important to encourage the development of personal responsibility, especially in young people (e.g., university students) as they move away from parental influence and begin making their own decisions (Harvey \& Retter, 2002). If young people are aware that their decisions and the consequent outcomes are their own, they are more likely to consider their choices carefully before making decisions. This awareness of personal responsibility should lessen the chance that they will act inappropriately and get undesirable consequences.

This research aimed to study the effect of using movies to enhance personal responsibility of university students. Movies were chosen because they are a significant part of teenage culture in contemporary societies (Hebert \& Neumeister, 2001). In addition, movies offer both cognitive and affective experiences. If movie scenes contain strong emotional content, they can provoke discussion, assessment of one's values, and assessment of self (Champoux, 1999). Niemiec and Wedding (2008) suggested that "the medium of film, more than any other art 
form, is able to portray the subtleties of the human mind - thoughts, emotions, instincts, and motives - and their impact on behavior (p. 5)." In sum, movies are an excellent vehicle for examining individuals' strengths and how they are developed and maintained (Niemiec \& Wedding, 2008). Thus, we propose that training with movies is a powerful tool for developing positive characteristics, such as personal responsibility. The objective of this study is to test the effectiveness of training with movies by addressing the following research question: "Can personal responsibility be developed through systematic movie-based training?" If the training with movies is effective, changes in participants' personal responsibility would be observed; no change would be observed if there was no training.

\section{Theoretical Background}

\subsection{Personal Responsibility}

Personal responsibility is a core virtue within positive psychology (Linley \& Maltby, 2009). Yet, the construct of personal responsibility does not have a clear definition in the literature, and few studies examine personal responsibility. Mergler and Patton (2007) examined how teenagers conceive and integrate the concept of personal responsibility into their lives. They concluded that personal responsibility consists of four components: (1) an awareness of, and control over, one's own thoughts and feelings; (2) an awareness of, and control over, behavioral choices; (3) a willingness to hold oneself accountable for one's behavior and its outcome (consequence); and (4) an awareness of, and concern for, the impact of one's behavior upon others. For the present study, we defined personal responsibility as: a person's belief that one is the master of one's own life; one is aware of and chooses one's own choices and goals; and one is willing to hold oneself accountable for one's behavior and its consequences.

Few research has investigated relationships of personal responsibility and individuals' behaviors and well-being. Langer and Rodin (1976) conducted a field experiment on a group of nursing home residents in order to investigate the effects of enhanced personal responsibility and choice. In the experimental group, a communication emphasizing responsibility for oneself was given to the participants, whereas a communication stressing the staff's responsibility for the residents was given to the participants in the control group. Moreover, the experimental group was given freedom to make their own choices and responsibility of caring for a plant. In contrast, the staff made decisions and took care of the plant for the control group. The study found that compared to the control group, the participants in the experimental group showed an important improvement on a general sense of well-being, active participation, and alertness.

In formal education, Martel, McKelvie, and Standing (1987) examined relationships among intelligence, personal responsibility, and academic performance of undergraduate students. Personal responsibility was measured by using the Responsibility scale of the California Psychological Inventory and a student-written scale of Personal Responsibility. The study found that personal responsibility and intelligence jointly predicted students' mean course grade, and that personal responsibility was the best single predictor.

Singg, Thomas, and Null (2005) investigated the relationship of student personal responsibility to academic dishonesty. In their study, the concept of student personal responsibility encompasses the concepts of integrity, maturity, proper conduct, and internalization of ethical behaviors. They found that personal responsibility was negatively correlated with academic dishonesty $(r=-.26, p<.01)$. Female students with high academic integrity had the highest sense of personal responsibility while females with high academic dishonesty had the lowest sense of personal responsibility. Nonetheless, no relationship between personal responsibility and academic dishonesty was found among male students.

Another study by Li, Wright, Rukavina, and Pickering (2008) examined the relationships between perceptions of personal and social responsibility and intrinsic motivation in physical education. Personal responsibility was defined in terms of effort and self direction. The results suggested that there was a positive relationship between personal responsibility and intrinsic motivation in physical education.

In sum, previous research has found positive effects of personal responsibility on individual behavior and well-being.

\subsection{Movies as a Training Resource}

Movies provide an excellent vehicle for educational and therapeutic purposes. Previous research advocates the use of film in the classroom and clinic (Niemiec \& Wedding, 2008). Educators who have experiences in using film as a teaching tool have also urged others to adopt this technique (Culkin, 1970; Maynard, 1977). Researchers have reported the success of using movies in teaching several courses, such as group dynamics, science, French, political science, and anthropology (Champoux, 1999). In the clinical setting, the term 
"cinematherapy" was coined by Berg-Cross, Jennings, and Baruch (1990) to describe the use of movies in psychotherapy. A significant amount of reports indicate that movies help providing role models, identifying and reinforcing strengths, facilitating communication, and building hope (Niemiec \& Wedding, 2008).

A notable benefit of movies is that they offer both cognitive and affective experiences. It is easier to get individuals to watch a movie than read a book, because it is easier to focus (Lanza, 1996). Previous research indicated that a person learns new, novel, and abstract concepts more easily when presented in both verbal and visual form (Salomon, 1979). Other research also shows that visual media make concepts more accessible to a person than text media and help with later recall (Cowen, 1984).

Research has also found that training with movies had positive effects in reducing anxiety, and increasing learning social skills (Allen, Danforth, \& Drabman, 1989; Ayres et al., 1993; Martin \& Jones, 1994). Moreover, a meta-analysis found that visual media using in nursing education had significant effects on attitude change and retention (Schermer, 1988). In the clinical setting, Powell, Newgent and Lee (2006) found that the combination of cinematherapy with coping-skills training had a more positive impact on self-esteem than coping skills training alone. In another experiment, Powell and Newgent (2010) employed a single subject interrupted time-series design. During a five-group session, participants watched the movie The Lord of the Rings: The Fellowship of the Ring, and themes of positivism were also highlighted. The study suggested that a structured, nondirective group cinematherapy intervention is clinically effective at decreasing hopelessness.

In sum, literature has shown that movies are an excellent tool for developing a variety of desired characteristics. Thus, based on research to date on effects of training with movie, it was hypothesized that personal responsibility can be developed in university students through systematic movie-based training, that is personal responsibility would significantly increase for participants in the training with movies groups but not for participants in the control group.

\section{Method}

\subsection{Participants}

This study used a pretest, posttest control group experimental design utilizing a homogeneous sample of 84 undergraduate student of a large public university in northern Thailand. All participants were registered in an introductory psychology course and received course credit for their participation. Participants were randomly assigned to two experimental groups and one control group. Twenty-eight students participated in experimental group 1, 26 in experimental group 2, and 30 in the control group. All of the participants ranged in age from 18 to 22 years, with a mean age of $19.42(S D=.97)$. In the total sample, 22 participants $(26.2 \%)$ were male and 62 participants $(73.8 \%)$ were female.

\subsection{Measures}

\subsubsection{Personal Responsibility Scale}

This 20-item questionnaire was developed by the authors to assess personal responsibility. The personal responsibility scale was developed by using the domain sampling model (Nunnally \& Bernstein, 1994). According to this model, a test is thought of as being a random sample of items relevant to the characteristic which the test measures. To develop such a test, researchers need to develop a theoretical definition for the concept domain, and identify its critical attributes. The concept of personal responsibility was defined by reviewing relevant literature to identify behaviors representing this concept. To identify critical attributes, this study proposes that individuals with personal responsibility would act in the following ways: (a) aware of one's desires and goals; (b) choose one's own choices and destiny; (c) initiate one's own action to achieve goals; and (d) willing to hold oneself accountable for one's behavior and its consequences.

The initial scale consisted of 35 items; example items include, "I know what is important for my life", "I am the one who determines my fate", and "I am willing to admit my mistakes to other people". Participants were asked to rate the extent to which statements described themselves on a 5-point scale $(0=$ "strongly disagree," $4=$ "strongly agree"). Three psychologists were invited to assess the content validity of the scale. They were asked to assess the items for language clarity and domain coverage. The criteria for accepting items were set a priori. All comments from the judges were also taken into consideration in the process of item selection.

An exploratory principal component factor analysis was conducted on a data of 300 university students. The results indicated that the assumptions for a factor analysis were met; the Barlett's Test of Sphericity was significant $\left(\chi^{2}=1705.47, d f=378, p=0.000\right)$, and the Kaiser-Meyer-Olkin measure of sampling adequacy was 0.779. The result of the principal component factor analysis with varimax rotation indicated that the measure 
composed of nine factors with an eigenvalue of 1.00 or greater and accounted for $57.84 \%$ of the variance. All items loaded onto at least one factor at the 0.40 level or above.

Parallel analysis (Horn, 1965) was also used to explore the initial number of factors using O'Connor's (2000) program. With parallel analysis, the size of eigenvalues from the obtained data was compared with eigenvalues produced by randomly generated data. This procedure continues extracting factors until the randomly generated data produces eigenvalues larger than the obtained data. Parallel analysis indicated that 4 factors should be extracted, which is congruent with the number of factors proposed by this study. Thus, we chose to extract 4 factors for the analyses that follow.

The authors considered both statistical results and theoretical foundations in determining and interpreting the number of items. We deleted items that did not load on any factor across the structures. Of the original 35 items, 15 items were discarded and 20 were retained. The remaining items were then factor analyzed again, resulting in the extraction of four factors with eigenvalues greater than 1, accounting for $50.21 \%$ of the variance. Cronbach's alpha coefficient for the total scale was $=.82$ and was also found acceptable for all four factors, ranging from .60 -.70 .

\subsubsection{Demographic Information}

The author developed a demographic information sheet asking participants to indicate their age, gender, and other information.

\subsection{Procedures}

All participants completed all questionnaires before the training sessions (Time 1). Interventions with both experimental groups were carried out in five weekly sessions by the authors. During each session, the experimental group 1 (movie+discussion) viewed a movie and participated in group discussion, the experimental group 2 (movie-only) viewed a movie only, and the control group did not receive any intervention. After the 5 -weekly sessions, all participants completed all post-test questionnaires (Time 2). One month after completion of the training sessions, all participants in the two experimental and one control group completed follow-up questionnaires (Time 3). Thus, the design of this study was as follows:

\begin{tabular}{|c|c|c|}
\hline Experimental group $1(\mathrm{R}) \mathrm{T}_{1}$ & $\mathrm{X} 1$ & $\mathrm{~T}_{2}$ \\
\hline Experimental group $2(\mathrm{R}) \mathrm{T}_{1}$ & $\mathrm{X} 2$ & $\mathrm{~T}_{2}$ \\
\hline Control group & & $\mathrm{T}_{2}$ \\
\hline
\end{tabular}

Note. $(\mathrm{R})=$ random sampling, $\mathrm{X} 1$ = watching movies and group discussion, $\mathrm{X} 2$ = watching movies only

To select the movies for enhancing personal responsibility in this study, the following three criteria were used:

(a) A vivid portrayal of personal responsibility; i.e., a willingness to hold oneself responsible for resulting outcomes and a sense of power and control to act on the world and achieve one's goals.

(b) A character that portrays how to subdue obstacles and maintain personal strengths.

(c) A mood in the movie that is uplifting and motivating.

Based on the above criteria, the following movies were selected:

(1) October Sky. The film is about "Homer Hickam", a coal miner's son who was inspired by the launch of "Sputnik 1", the first artificial satellite. With the help of his friends, Homer sets out to build rockets of his own.

(2) The Fighter. It is a drama about a boxer who struggled to become the world light welterweight champion.

(3) Cool Runnings. It is based on the true story of the first Jamaican bobsled team who tried to compete in the Winter Olympics.

(4) The Pursuit of Happiness. The film is based on the true story of Chris Gardner, a salesman who tried to build a future for himself and his 5-year-old son, eventually became a millionaire.

(5) Top Secret (a Thai film). Based on a true story, the movie is about a Thai teenager who turned himself from an online game addict disparaged by teachers to a famous young billionaire.

Experimental group 1 and 2 viewed these five movies. In addition, experimental group 1 participated in a 40-minute elaboration session about personal responsibility after viewing each movie. In each group discussion session, the following questions were used as discussion points: (a) How do you feel about the movie? (b) Who was your favorite character? Why? (c) What do you learn from the movie? (d) How would you apply the lessons 
learned from the movie to your life? (e) What do you think about personal responsibility? (f) How can we develop our personal responsibility?

While experimental group 2 watched the movies, they did not participate in the group discussion. After each session, participants in both experimental group 1 and 2 were requested to answer three-short questions asking their feelings about the movie, what they learned from the movie, and how they would apply the lessons learned from the movie to their lives.

For the control group, participants were requested to answer pre-test, post-test, and follow-up questionnaires without receiving any intervention. Most participants in the control group answered all questionnaires in a meeting room. Due to some inconvenience, a few participants, however, were allowed to fill out the questionnaires by mail.

\section{Results}

\subsection{Preliminary Analysis}

After checking for missing data, the statistical analyses were performed on a final sample of 84 participants at pre-training, 84 participants at post-training and 53 participants at the 1-month follow-up. The means and standard deviations for personal responsibility for all groups over 3-time periods are shown in Table 1.

Prior to the statistical analyses, initial equivalence between the three groups was determined by using analysis of variance. The result showed that a random assignment was effective in establishing initial equivalence between the three groups, as no significant differences $(p=.588)$ were found among their levels of personal responsibility, gender, age, and grade point average (see Table 2).

\subsection{Hypotheses Testing}

It was hypothesized that personal responsibility would significantly increase for participants in the two experimental groups but not for subjects in the control group. To test this hypothesis, we created two change variables using the following formulas: (1) PRC1 = PR post-training score $-\mathrm{PR}$ pre-training score; (2) PRC2 = PR 1-month follow-up score - PR pre-training score. Two one-way analysis of variance were conducted to examine the effects of group on personal responsibility from pre-training to post-training and from post-training to 1-month follow-up. In both analyses, the independent variable was group, for the first analysis the dependent variable was PRC1, and for the second analysis the dependent variables was PRC2. Preliminary checks indicated that the assumptions of homogeneity of variance, linearity, normality, and independence of observations were met.

Table 1. Descriptive statistics for all groups for all three-time periods

\begin{tabular}{|c|c|c|c|c|}
\hline \multirow{2}{*}{ Time Period } & \multirow{2}{*}{ Group } & \multirow{2}{*}{$N$} & \multicolumn{2}{|c|}{ Personal Responsibility } \\
\hline & & & $M$ & $S D$ \\
\hline \multirow[t]{4}{*}{ Pre-training } & Movie+discussion & 28 & 2.87 & 0.34 \\
\hline & Movie only & 26 & 2.89 & 0.38 \\
\hline & Control & 30 & 2.95 & 0.33 \\
\hline & Total & 84 & 2.90 & 0.35 \\
\hline \multirow[t]{4}{*}{ Post-training } & Movie+discussion & 28 & 3.08 & 0.37 \\
\hline & Movie only & 26 & 3.09 & 0.39 \\
\hline & Control & 30 & 2.94 & 0.37 \\
\hline & Total & 84 & 3.04 & 0.38 \\
\hline \multirow[t]{4}{*}{ 1-month follow-up } & Movie+discussion & 26 & 3.16 & 0.38 \\
\hline & Movie only & 15 & 3.00 & 0.44 \\
\hline & Control & 12 & 3.10 & 0.32 \\
\hline & Total & 53 & 3.08 & 0.38 \\
\hline
\end{tabular}

Note. Different sample sizes during the three-time periods are due to participants' voluntary withdrawal

Table 2. ANOVA to validate initial equivalence among the two experimental and one control groups

\begin{tabular}{lccrrr}
\hline \multirow{2}{*}{ Source } & Movie+discussion & Movie only & Control & \multirow{2}{*}{$F$ test } & \multirow{2}{*}{$p$ value } \\
\cline { 2 - 4 } & $M$ & $M$ & $M$ & 2.95 & .535 \\
.588 \\
PR (pre-training) & 2.86 & 2.89 & 1.67 & .788 & .458 \\
Gender & 1.81 & 1.73 & 19.23 & 2.392 & .098 \\
Age & 19.74 & 19.27 & 3.05 & .611 & .545 \\
GPA & 3.03 & 2.90 & &
\end{tabular}

Note. $\mathrm{PR}=$ personal responsibility, GPA=grade point average 
Results shown in Table 3 show that from pre-training to post-training, there was a significant difference in personal responsibility for the three groups $(F(2,83)=6.675, p=.002)$. The effect size, calculated using $\eta^{2}$, was .14 indicating a moderate difference in the mean scores of the groups. Post-hoc comparisons indicated that the mean personal responsibility change scores for participants assigned to the movie+discussion group $(M=.21$, $S D=.27)$ and the movie-only group $(M=.20, S D=.22)$ were significantly higher than for participants in the control group $(M=-.01, S D=.27)$.

Table 3. ANOVA results for effects of training with movies on personal responsibility from pre-training to post-training and from post-training to 1-month follow-up

\begin{tabular}{llccccc}
\hline & & $S S$ & $d f$ & $M S$ & $F$ & $p$ \\
\hline \multirow{3}{*}{ PRC1 } & Between Groups & .846 & 2 & .423 & 6.675 & .002 \\
& Within Groups & 5.135 & 81 & .063 & & \\
& Total & 5.982 & 83 & & & .005 \\
\multirow{3}{*}{ PRC2 } & Between Groups & .726 & 2 & .363 & 5.935 & \\
& Within Groups & 3.057 & 50 & .061 & & \\
& Total & 3.783 & 52 & & & \\
\hline
\end{tabular}

Note. PRC1 = PR post-training score - PR pre-training score; PRC2 = PR 1-month follow-up score - PR pre-training score

Personal responsibility for the three groups from pre-training to 1-month follow-up was also significantly different $(F(2,50)=5.935, p=.005)$. The effect size, calculated using $\eta^{2}$ was .19 indicating a moderate difference in the mean change scores of the groups. Post-hoc comparisons indicated that the mean personal responsibility change scores for participants assigned to the movie+discussion group $(M=.31, S D=.27)$ were significantly higher than for participants in the control group $(M=.01, S D=.20)$. No difference was found between the movie+discussion and movie-only groups, and between the movie-only and control groups.

Since the analysis focused on mean differences between the experimental and control groups, we conduct two analyses of covariance (ANCOVA). The first ANCOVA uses the posttest scores on personal responsibility as the dependent measures and the pretest score on personal responsibility as the covariate. Results shown in Table 4 suggest that the group variable (two-typed of training or control conditions) was a significant predictor of personal responsibility at post-training $(F(2,80)=7.247, p<.001)$. Post-hoc analysis of the univariate outcome showed that the two training groups had higher levels of personal responsibility than the control group $(p \mathrm{~s}<.01)$.

Table 4. ANCOVA result using the post-training score as the dependent measure, controlling for personal responsibility score at pre-training

\begin{tabular}{lccrrr}
\hline \multicolumn{1}{c}{ Source } & \multicolumn{1}{c}{$S S$} & $d f$ & \multicolumn{1}{c}{$M S$} & \multicolumn{1}{c}{$F$} \\
\hline Corrected Model & $7.295^{*}$ & 3 & 2.432 & 40.034 & .000 \\
Intercept & .442 & 1 & .442 & 7.276 & .009 \\
PR1 & 6.905 & 1 & 6.905 & 113.670 & .000 \\
GR & .751 & 2 & .375 & 6.181 & .003 \\
Error & 4.860 & 80 & .061 & \\
Total & 785.655 & 84 & & \\
Corrected Total & 12.155 & 83 & & \\
\hline
\end{tabular}

Note. PR1=personal responsibility score at pre-training, $* R$ Squared $=.600($ Adjusted $R$ Squared $=.585)$

Table 5. ANCOVA result using the 1-month follow-up score as the dependent measure, controlling for personal responsibility score at pre-training

\begin{tabular}{lccrrr}
\hline \multicolumn{1}{c}{ Source } & \multicolumn{1}{c}{$S S$} & $d f$ & \multicolumn{1}{c}{$M S$} & \multicolumn{1}{c}{$F$} \\
\hline Corrected Model & $4.920^{*}$ & 3 & 1.640 & 27.704 & .000 \\
Intercept & .290 & 1 & .290 & 4.902 & .032 \\
PR1 & 4.680 & 1 & 4.680 & 79.063 & .000 \\
GR & .535 & 2 & .267 & .519 & .016 \\
Error & 2.900 & 49 & .059 & \\
Total & 519.323 & 53 & & \\
Corrected Total & 7.820 & 52 & & \\
\hline
\end{tabular}

Note. PR1=personal responsibility score at pre-training, $* R$ Squared $=.629($ Adjusted $R$ Squared $=.606)$ 
In addition, at the 1-month follow-up period (Table 5), the group variable (two-typed of training or control conditions) was also a significant predictor of personal responsibility $(F(2,47)=3.687, p<.001)$. Post-hoc analysis of the univariate outcome showed that the movie+discussion group had a higher level of personal responsibility than the control group $(p<.05)$. No difference was found between the movie-only and control groups.

\section{Discussion}

The objective of this study was to determine whether systematic movie-based training program could effectively develop personal responsibility. Specifically, the research question was whether personal responsibility could be effectively developed in a five-period movie training program. Through a pretest, posttest control group experimental design, the two training groups experienced a significant increase in personal responsibility, while the randomly assigned control group that did not receive any training, did not show a significant increase in personal responsibility. In addition, results of the ANCOVA demonstrated that the systematic movie-based training positively developed personal responsibility, as the group variable predicted personal responsibility at post-training and 1-month follow-up periods while controlling for pre-training scores. Overall, the results of this experimental study provide support that personal responsibility can be developed through a five-period movie training program.

The findings that systematic movie-based training program increased personal responsibility adds further support to a number of previous findings (e.g., Ayres et al., 1993; Martin \& Jones, 1994; Powell \& Newgent, 2010), which have shown that movies are a powerful tool for enhancing positive characteristics and reducing negative ones. This is because the appropriate movies speak to the 'unspoiled spot that is present in all of us, where people escape from their lives into themselves and come out feeling better, stronger, and more willing to take healthy action' (Niemiec \& Wedding, 2008, p. 8). Moreover, the dialogue, camera angles, music, lighting, and sound effects of a movie synergistically induce viewers to be in a trance-like state. Thus, viewers are likely to be influenced by behaviors being portrayed in the movie. Consequently, viewers leave the movie with new ideas about values and behaviors they need to develop and strengthen.

Although a significant effect was found from pre to post-intervention in the movie-only group, no significant effect was found at 1-month follow-up. This could be due to the attrition rate of participants in the movie-only group. In addtition, even though watching positive movies alone enhanced personal responsibility, this effect may deteriorate over time. As shown in this study, the movie effect on participants lasted longer when integrating group discussion into the training sessions.

In terms of internal validity, a notable strength of this study was the random assignment of participants into experimental and control groups. Random assignment assumes that there is initial equivalence on all potentially confounding variables in the study, and analysis of the Time 1 levels of personal responsibility showed no significant difference between the two experimental and control groups. In terms of external validity, we think that the effect of systematic movie-based training may not be limited to only these particular participants. It is possible that this effect would apply to other ethnic or demographic groups. Overall, given the strengths of the randomized pretest, posttest control group design, the results can generally rule out alternative explanations. However, there are some limitations of this study.

First, this study examined the short-term effects of systematic movie-based training program. Future research might examine whether the benefits of systematic movie-based training program are maintained over longer time periods. Second, the use of self-report measures in this study is subject to social desirability effects. Participants might respond social desirably even though their anonymities are guaranteed. Third, the only dependent variable in this study was personal responsibility; other specific behaviors or characteristics were not studied. Thus, future research should include other important characteristics. In conclusion, although the present study must be replicated in order to firmly establish the generalizability of the findings, this study suggests that systematic movie-based training program may have significant effects on personal responsibility. If the replications are successful, the usefulness of systematic movie-based training program would be extended.

The results of the present study have some practical implications. It suggests that individuals' personal responsibility may be enhanced using systematic movie-based training program - a relatively inexpensive and convenient, yet effective intervention.

\section{References}

Allen, K. D., Danforth, J. S., \& Drabman, R. S. (1989). Videotaped modeling and film distraction for fear reduction in adults undergoing hyperbaric oxygen therapy. Journal of Consulting and Clinical Psychology, 
57, 554-558. http://dx.doi.org/10.1037/0022-006X.57.4.554

Ayres, J., Ayres, F. E., Baker, A. L., Colby, N., De Blasi, C., Dimke, D., Docken, L., ...Wilcox, A. K. (1993). Two empirical tests of a videotape designed to reduce public speaking anxiety. Journal of Applied Communication Research, 21, 132-147. http://dx.doi.org/10.1080/00909889309365362

Berg-Cross, L., Jennings, P., \& Baruch, R. (1990). Cinematherapy: Theory and application. Psychotherapy in Private Practice, 8, 135-156.

Champoux, J. E. (1999). Film as a teaching resource. Journal of Management Inquiry, 8(2), 240-251. http://dx.doi.org/10.1177/105649269982016

Cowen, P. S. (1984). Film and text: Order effects in recall and social inferences. Educational Communication and Technology, 32, 131-144.

Culkin, J. M. (1970). Films deliver. In A. Schillaci, \& J. M. Culkin (Eds.), Films deliver: Teaching creatively with film (pp. 19-29). New York: Citation Press.

Gagliano, M. E. (1988). A literature review on the efficacy of video in patient education. Journal of Medical Education, 63, 785-795.

Gerrig, R. J., \& Prentice, D. A. (1996). Notes on audience response. In D. Bordwell \& N. Carroll (Eds.), Post-theory: Reconstructing film studies (Chapter 18). Madison, WI: The University of Wisconsin Press.

Harvey, V. S., \& Retter, K. (2002). Variations by gender between children and adolescents on the four basic psychological needs. International Journal of Reality Therapy, 21(2), 33-36.

Hebert, T. P., \& Neumiester, K. L. (2001). Guided viewing of film: A strategy for counseling gifted teenagers. Journal of Gifted Education. 12(4), 224-236.

Horn, J. L. (1965). A rationale and test for the number of factors in factor analysis. Psychometrika, 30, 179-185. http://dx.doi.org/10.1007/BF02289447

Langer, E., \& Rodin, J. (1976). The effects of choice and enhanced personal responsibility for the aged: A field experiment in an institutional setting. Journal of Personality and Social Psychology, 134, 191-198. http://dx.doi.org/10.1037/0022-3514.34.2.191

Lanza, M. L. (1996). Bibliotherapy and beyond. Perspectives in Psychiatric Care, 32, 12-14. http://dx.doi.org/10.1111/j.1744-6163.1996.tb00493.x

Li, W., Wright, P. M., Rukavina, P., \& Pickering, M. (2008). Measuring students' perceptions of personal and social responsibility and the relationship to intrinsic motivation in urban physical education. Journal of Teaching in Physical Education, 27, 167-178.

Linley, P. A., \& Maltby, J. (2009). Personal responsibility. In S. J. Lopez (Ed.), The encyclopedia of positive psychology (pp. 685-689). Boston, MA: Blackwell Publishing.

Martel, J., McKelvie, S. J., \& Standing, L. (1987). Validity of an intuitive personality scale: Personal responsibility as a predictor of academic achievement. Educational and Psychological Measurement, 47(4), 1153-1163. http://dx.doi.org/10.1177/0013164487474033

Martin, A., \& Jones, E. (1994). Comparing interactive videodisc instruction with traditional methods of social skills training. Education and Training Technology International, 31, 187-195. http://dx.doi.org/10.1080/0954730940310304

Maynard, R. A. (1977). Classroom cinema. New York: Teachers College, Columbia University.

Mergler, A. G., Spencer, F. H., \& Patton, W. A. (2007). Development of a measure of personal responsibility for adolescents. Retrieved September, 22, 2013, from http://eprints.qut.edu.au/10743/1/10743a.pdf

Niemiec, R. M., \& Wedding, D. (2008). Positive psychology at the movies: Using films to build virtues and character strengths. Cambridge, MA: Hogrefe.

Nunnally, J. C., \& Bernstein, I. F. (1994). Psychometric theory. New York: McGraw-Hill.

O'Connor, B. P. (2000). SPSS and SAS programs for determining the number of components using parallel analysis and Velicer's MAP test. Behavior Research Methods, Instrumentation, and Computers, 32, 396-402. http://dx.doi.org/10.3758/BF03200807

Powell, M. L., \& Newgent, R. A. (2010). Improving the empirical credibility of cinematherapy: A single-subject interrupted time-series design. Counseling Outcome Research and Evaluation, 1(2), 40-49. 
http://dx.doi.org/10.1177/2150137810373920

Powell, M. L., Newgent, R. A., \& Lee, S. M. (2006). Group cinematherapy: Using metaphor to enhance adolescent self-esteem. Arts in Psychotherapy, 33, 247-253. http://dx.doi.org/10.1016/j.aip.2006.03.004

Salomon, G. (1979). Interaction of media, cognition and learning: An exploration of how symbolic forms cultivate mental skills and affect knowledge acquisition. San Francisco: Jossey-Bass.

Schermer, J. (1988). Visual media, attitude formation, and attitude change in nursing education. Educational Communication and Technology, 36, 197-210.

Singg, S., Thomas, S., \& Null, M. (2005). Relationship between academic dishonesty and student personal responsibility. American Association of Behavioral and Social Sciences, 8(3). Retrieved from http://aabss.org/Perspectives2005/AABSS\%20Article\%206\%20RELATIONSHIP.pdf

\section{Copyrights}

Copyright for this article is retained by the author(s), with first publication rights granted to the journal.

This is an open-access article distributed under the terms and conditions of the Creative Commons Attribution license (http://creativecommons.org/licenses/by/3.0/). 